\title{
Low Temperature Synthesis of Magnesium Oxide and Spinel Powders by a Sol-Gel Process
}

\author{
Li-Zhai Pei ${ }^{\mathrm{a},}$, Wan-Yun Yin ${ }^{\mathrm{b}}$, Ji-Fen Wang ${ }^{\mathrm{a}}$,Jun Chen ${ }^{\mathrm{a}}$,Chuan-Gang Fan, Qian-Feng Zhang ${ }^{\mathrm{a}, \mathrm{b}}$ \\ ${ }^{a}$ School of Materials Science and Engineering, Institute of Molecular Engineering and Applied \\ Chemistry, Key Lab of Materials Science and Processing of Anhui Province, \\ Anhui University of Technology, Ma'anshan, Anhui 243002, P. R. China \\ ${ }^{\mathrm{b}}$ Technique Center, China MCC17 Group Co., Ltd, Ma'anshan, Anhui 231001, P. R. China
}

Received: January 26, 2010; Revised: June 18, 2010

\begin{abstract}
Magnesium oxide and magnesium aluminate $\left(\mathrm{MgAl}_{2} \mathrm{O}_{4}\right)$ spinel (MAS) powders have been synthesized by a simple aqueous sol-gel process using citrate polymeric precursors derived from magnesium chloride, aluminium nitrate and citrate. The thermal decomposition of the precursors and subsequent formation of cubic $\mathrm{MgO}$ and MAS were investigated by X-ray diffraction (XRD), scanning electron microscopy (SEM), thermogravimetrydifferential scanning calorimetry (TG-DSC) and Fourier transform infrared spectra (FTIR). The single phase cubic $\mathrm{MgO}$ powder and MAS powder form after heat treatment at 800 and $1200{ }^{\circ} \mathrm{C}$, respectively. The particle size of the $\mathrm{MgO}$ and MAS powders is about $100 \mathrm{~nm}$ and several micrometers, respectively. Ball milling eliminates the size of $\mathrm{MgO}$ and $\mathrm{MgAl}_{2} \mathrm{O}_{4}$ spinel powders by decreasing the conglomeration of the powders.
\end{abstract}

Keywords: magnesium oxide, spinel, sol-gel, characterization

\section{Introduction}

Magnesium oxide is a traditional raw material for use in a wide range of products, e.g. refractory, paints, paper, plastics, rubber, oil, pharmaceutical, fertilizer, animal feed, additive in superconductor products, waste treatment agent for neutralizing acids or cleaning water and as a catalyst material ${ }^{1,2}$. Most commercial $\mathrm{MgO}$ powders are synthesized by the calcinations of forms of $\mathrm{Mg}(\mathrm{OH})_{2}$, such as brucite or precipitate from sea water, and thermal decomposition of $\mathrm{MgCO}_{3}$, such as magnesite ${ }^{3}$. In such powders, the primary particles remain aggregated, usually in a shape similar to that of the precursor compound. The calcination at higher temperature destroys the agglomeration due to the propagation of cracks resulting in the formation of finely dispersed powders. However, calcination at higher temperature also increases the crystal size of the powders and reduce the surface area. For more specific applications, an inexpensive method to synthesize finer and less aggregated powders with controllable structure and morphology is necessary. For instance, fine powders can facilitate component sintering at lower temperature for refractories while the ratio of high surface area to volume of the powder may provide a higher activity as catalyst and higher removal efficiency in waste water treatment ${ }^{2}$. Some groups have devoted to the synthesis of fine $\mathrm{MgO}$ powders ${ }^{4,5}$. However, theses methods take the disadvantages of complex process, expensive cost etc. One effective method to synthesize fine $\mathrm{MgO}$ powders is the sol-gel process ${ }^{6}$. Klabunde et al. ${ }^{7}$ prepared $\mathrm{MgO}$ powders with the average size of about $5 \mathrm{~nm}$ and ultrahigh surface area via a sol-gel process followed by a hypercritical drying procedure. However, the need to synthesize and handle the costly and hazardous metal-organic precursors in the solgel procedure seems inconvenient and is not economically acceptable.

Magnesium aluminate $\left(\mathrm{MgAl}_{2} \mathrm{O}_{4}\right)$ spinel (MAS) has also received a great deal of attention as a technologically important material on account of its attractive properties such as high melting point, high mechanical strength at elevated temperature, high chemical inertness and good thermal shock resistance which has been extensively used for various purposes, such as refractory material and humidity sensor etc. ${ }^{8}$. However, it is very difficult to synthesize fine spinel powders with high purity from conventional solid-state reaction route since the technique requires repeated grinding and calcination steps to get the desired properties, which invariably contaminate the powders. Although some methods, such as hydrothermal synthesis, plasma spray decomposition of oxides could be used to prepare high-purity oxide powders. However, these techniques have not received much commercial importance because of the use of expensive raw materials and many processing steps ${ }^{9,10}$.

In this paper, a relatively simple, efficient, low-cost aqueous solgel process based on the in situ generation of water soluble metal complexes with magnesium chloride, aluminum nitrate and citric acid as raw materials has been developed to synthesize fine magnesium oxide and spinel powders. Decomposition of the citrate precursor and morphology of the synthesized powders are investigated.

\section{Experimental}

Analytical grade $\mathrm{MgCl}_{2}, \mathrm{Al}\left(\mathrm{NO}_{3}\right)_{3} \cdot \mathrm{H}_{2} \mathrm{O}$ and $\mathrm{C}_{6} \mathrm{H}_{8} \mathrm{O}_{7} \cdot \mathrm{H}_{2} \mathrm{O}$ (Tianjin Benchmark Chemical Reagent Co., Ltd., Tianjin, China) were used as the raw materials to prepare magnesium oxide and MAS powders. The starting solution was prepared by dissolving magnesium chloride, aluminum nitrate and citric acid into deionized water. The concentration of nitrate was $0.5 \mathrm{M}$. The molar ratio of citric acid to metal ions ratio is $3: 1$ in the solution. The solution was continuously stirred for 2 hours and kept at a temperature of $60^{\circ} \mathrm{C}$ until it turned to a yellowish sol. Then the stabilized nitrate-citrate sol was rapidly heated to $100{ }^{\circ} \mathrm{C}$ and stirred constantly. Viscosity and color changed as the sol turned into a transparent stick gel. The gel was heat treated at $150{ }^{\circ} \mathrm{C}$ for 2 hours and a fluffy, polymeric citrate precursor was gained. Finally, the synthesized precursor was ground to a fine powder and calcined at different temperature for 2 hours in muffle furnace. 
Phase identification was performed by a Siemens D5000 X-ray diffractometer (XRD) equipped with a graphite mono-chromatized $\mathrm{Cu}-\mathrm{K} \alpha$ radiation $(\lambda=1.5406 \AA)$. The samples were scanned at a scanning rate of $0.05 \%$ in the $2 \theta$ range of $10^{\circ}-90^{\circ}$. SEM observation was performed using JEOL JSM5410 SEM with a 15-KV accelerating voltage. Fourier transform infrared spectra (FTIR) spectroscopy (Perkin Elmer PE.One WQF-410 spectrometer) was used at room temperature in the range of $450-4000 \mathrm{~cm}^{-1}$ with a resolution of $4 \mathrm{~cm}^{-1}$. Thermal analysis of the precursor was done by thermogravimetrydifferential scanning calorimetry (TG-DSC) on a Netzsch STA 449C instrument. The mass spectra (MS) of the gaseous products evolving from the precursor in TG-DSC are simultaneously monitored with a Balzers termostar ${ }^{\mathrm{TM}}$ quadrupole mass spectrometer.

\section{Results and Discussion}

Figure 1 shows the XRD patterns of the as-synthesized magnesium oxide and MAS powders obtained by heat treatment of the precursors at 800 and $1200^{\circ} \mathrm{C}$ for 2 hours, respectively. According to the JCPDS card (JCPDS card, No. 45-0946), the phase of the powders (Figure 1a) obtained from magnesium precursor can be indexed to be cubic $\mathrm{MgO}$ structure which is consistent with the results reported in the literatures ${ }^{3-6}$. The intense peaks show that the powders are

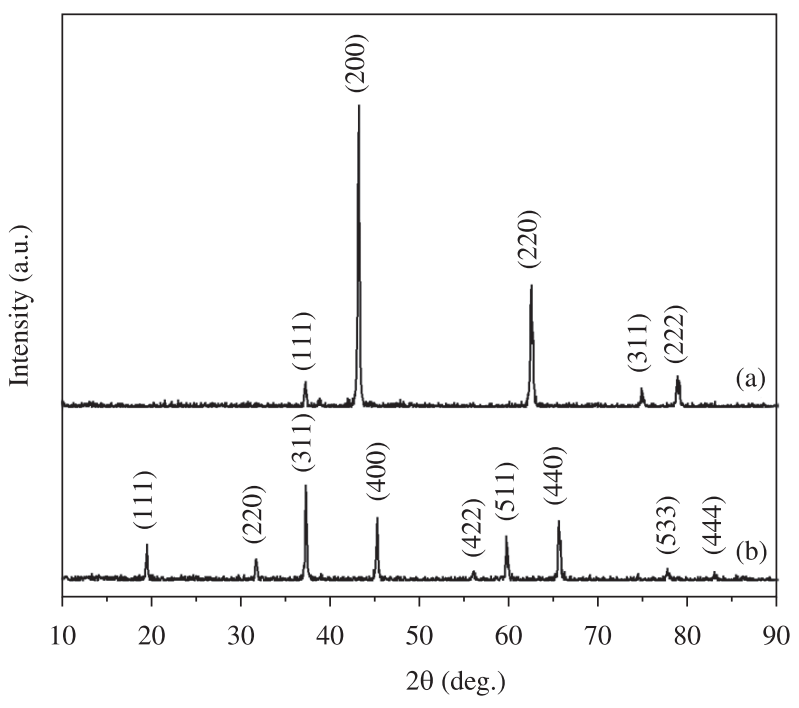

Figure 1. X-ray diffraction patterns of the $\mathrm{MgO}$ and MAS powders. a) $\mathrm{MgO}$ powder after heat treatment at $800^{\circ} \mathrm{C}$; and b) MAS powder after heat treatment at $1200{ }^{\circ} \mathrm{C}$.

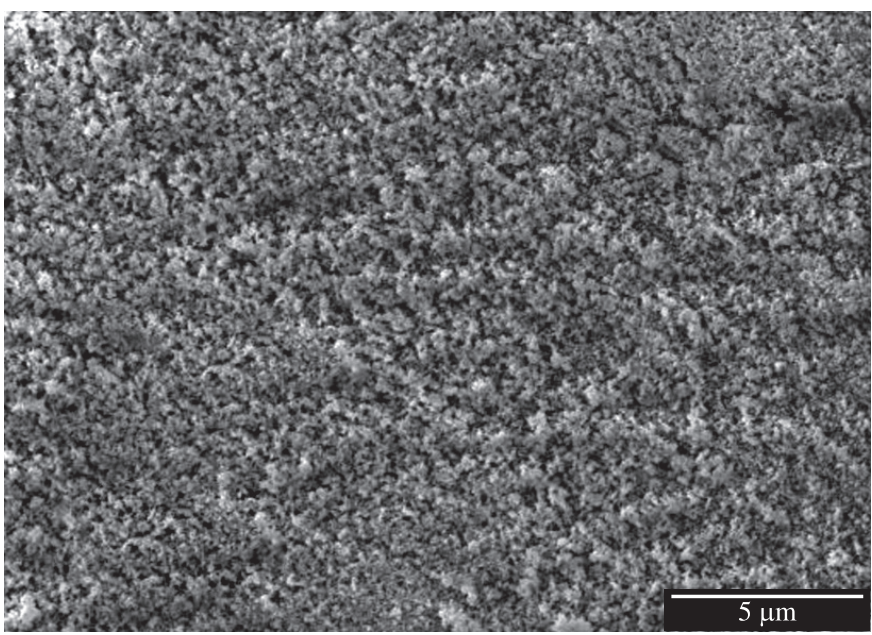

(a)

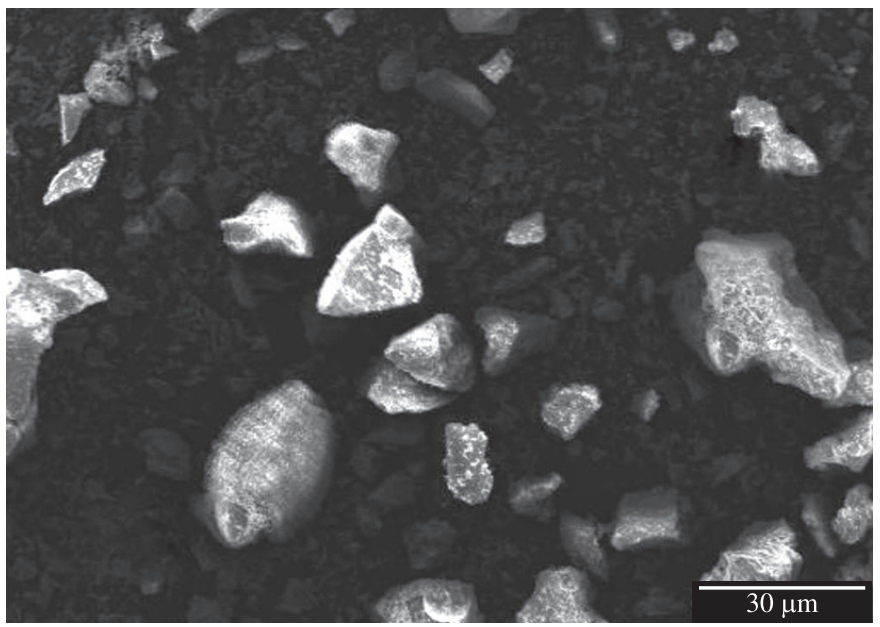

(c)

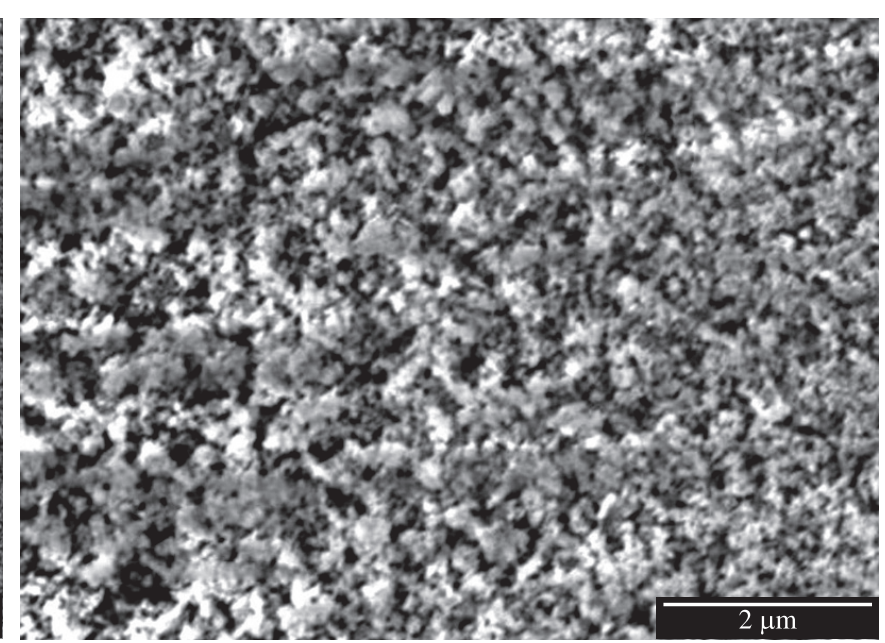

(b)

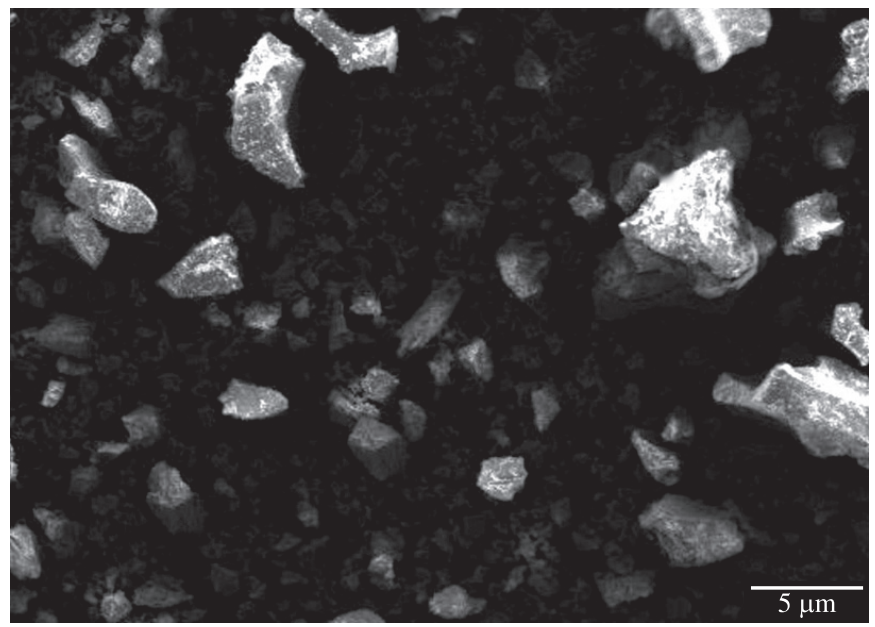

(d)

Figure 2. SEM images of the $\mathrm{MgO}$ and MAS powders. a) and b) MgO powder; and c) and d) MAS powder. 


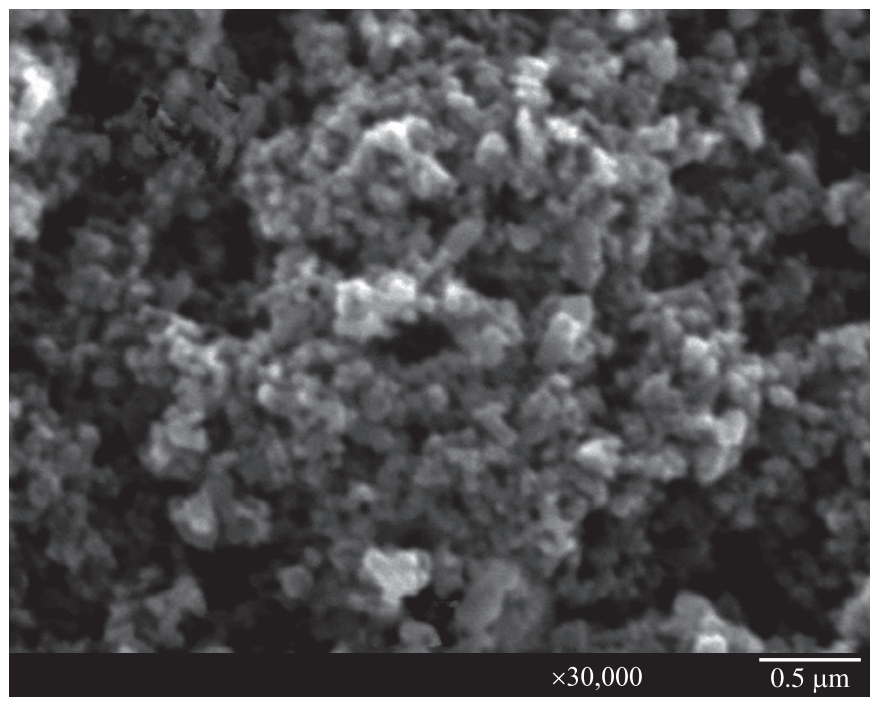

(a)

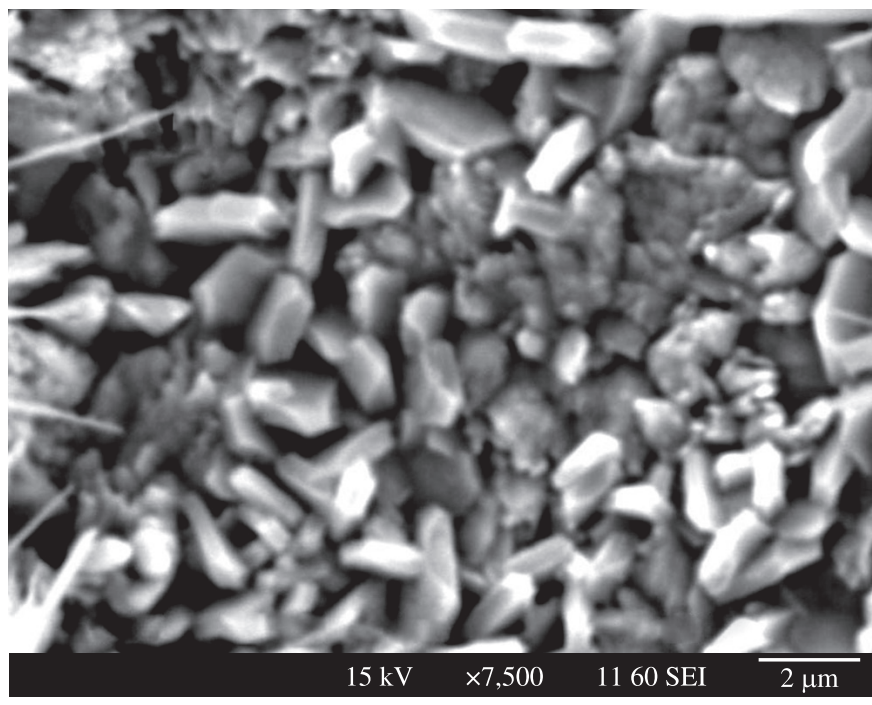

(b)

Figure 3. SEM images of the samples treated by ball milling for 12 hours. a) $\mathrm{MgO}$ powder; and b) MAS powder.

high crystalline. The powders obtained from the MAS precursor are composed of MAS cubic structure (JCPDS card, No. 21-1152) which is similar to those reported by Ganesh and Pati et al. ${ }^{910}$. No other diffraction peaks are detected showing the high pure phase.

The morphology and size of the powders are analyzed by SEM observation. The average diameter of the $\mathrm{MgO}$ powders with regular sphere particles (Figure 2a and b) is about $100 \mathrm{~nm}$. However, some particles are in microns size. These results demonstrate that the fine $\mathrm{MgO}$ powders can be prepared by the simple sol-gel process using $\mathrm{MgCl}_{2}$. The MAS powders with irregular morphology obtained from MAS precursor (Figure 2c and d) exhibit definite distribution in the size range of microns. The size of the most particles is less than $2 \mu \mathrm{m}$. However, the size of a small amount of powders is larger than $10 \mu \mathrm{m}$ (Figure 2c). Obviously, the aggregation phenomenon can be observed by the SEM images which may originate from the powder aggregation under high temperature sintering conditions. In order to further refine the powders, the ball milling (raw materials: balls: water $=1: 2.5: 1.5$ ) experiment was conducted. Figure 3 shows the SEM images of the $\mathrm{MgO}$ powder (a) and $\mathrm{MgAl}$ spinel powder (b) treated by ball milling for 12 hours. The particle size of the powders decreases obviously. The average particle size of the $\mathrm{MgO}$ and $\mathrm{MgAl}$ spinel powders is about $70 \mathrm{~nm}$ and $2 \mu \mathrm{m}$, respectively. The strong agglomerated phenomenon of the powders is considered to be caused by the high sintering temperature. The kind of agglomeration is relatively loose and can be dispersed after ball milling. The results show that the ball milling can relieve the agglomeration phenomenon of the powders obviously refining the powders.

The FTIR spectra at $450-4000 \mathrm{~cm}^{-1}$ for the Mg precursor and MAS precursor calcined at different temperature are shown in Figure 4. This clearly shows a broad absorption at $3000-3800 \mathrm{~cm}^{-1}$ with the absorption peak of $3441,3435,3437,3443$ and $3438 \mathrm{~cm}^{-1}$, respectively, which is the characteristic stretching vibration of hydroxylate $(-\mathrm{OH})$. Peaks localized at $1631-1637 \mathrm{~cm}^{-1}$ and $1383-1385 \mathrm{~cm}^{-1}$, respectively in Figure $4 \mathrm{a}-\mathrm{e}$ are assigned to asymmetrical and symmetrical stretching vibration of carboxylate $(\mathrm{O}-\mathrm{C}=\mathrm{O})$. No characteristic band of nitrate ions at $1464 \mathrm{~cm}^{-1}$ is observed from the FTIR spectra indicating the complete decomposition of $\mathrm{Mg}$ precursor and MAS precursor during the heat treating process with different temperature. In the FTIR spectum (Figure 4c) of the $\mathrm{MgO}$ powder calcined at $800{ }^{\circ} \mathrm{C}$,

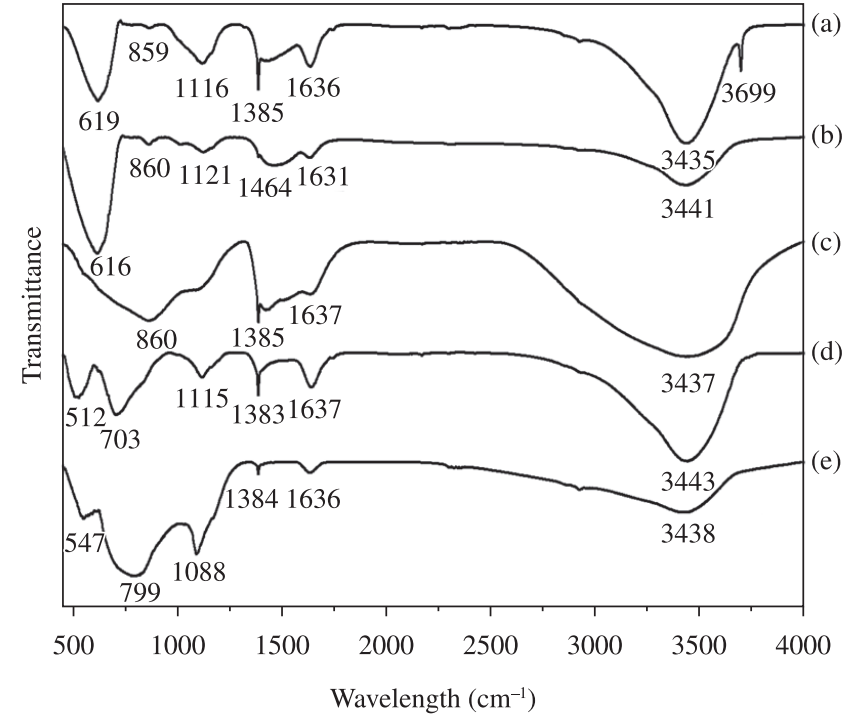

Figure 4. FTIR spectra of the Mg-citrate precursor and MAS precursor calcined at different temperature. a) $\mathrm{Mg}$ precursor calcined at $400{ }^{\circ} \mathrm{C}$; b) $\mathrm{Mg}$ precursor calcined at $600{ }^{\circ} \mathrm{C}$; c) $\mathrm{Mg}$ precursor calcined at $800{ }^{\circ} \mathrm{C}$; d) MAS precursor calcined at $800{ }^{\circ} \mathrm{C}$; and e) MAS precursor calcined at $1200{ }^{\circ} \mathrm{C}$.

the absorption bands of $\mathrm{NO}_{3}-$ group at 616 and $619 \mathrm{~cm}^{-1}$ disappear because of the complete decomposition of nitrate. Furthermore, the band of the carboxylate reduces obviously due to the decomposition of the citrate precursor. No characteristic bands with the asymmetrical and symmetrical stretching vibration at 1264 and $1068 \mathrm{~cm}^{-1}$ of the C-O-C group ${ }^{11}$ are observed from the FTIR spectra, indicating the thermal decomposition of polyester. However, the absorption peaks at $1115-1121 \mathrm{~cm}^{-1}$ are also observed from the spectra showing the $\mathrm{C}-\mathrm{O}$ absorption. With the calcination temperature increasing to $800^{\circ} \mathrm{C}$, the $\mathrm{C}-\mathrm{O}$ absorption peak vanishes. The absorption bands at 859 and $860 \mathrm{~cm}^{-1}$ (Figure $4 \mathrm{a}$ and $\mathrm{b}$ ) are contributed to the characteristic absorption peaks of cubic $\mathrm{MgO}$ showing the initial formation of cubic $\mathrm{MgO}$ above $400{ }^{\circ} \mathrm{C}$. With the increase of the calcination 


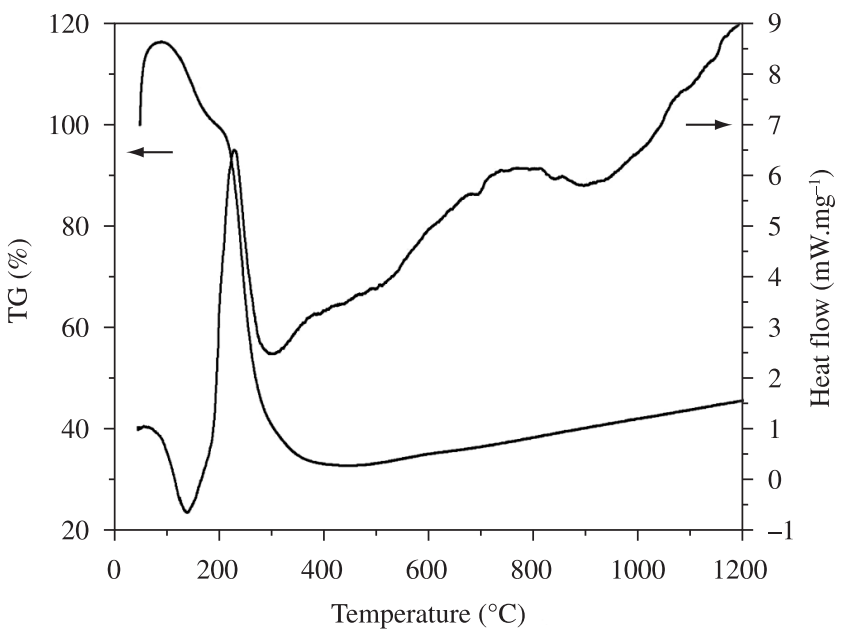

Figure 5. TG-DSC curve of the as-synthesized Mg precursor.

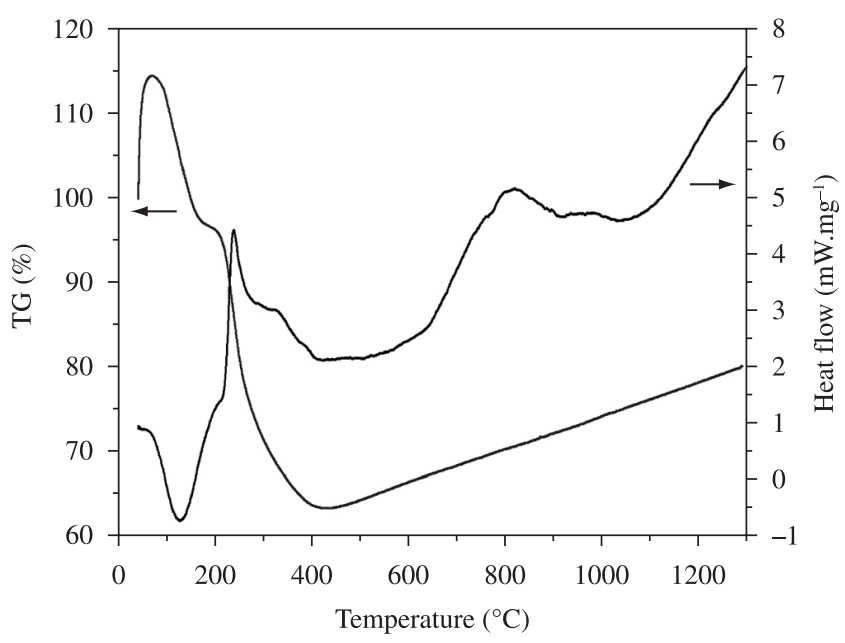

Figure 6. TG-DSC curve of the as-synthesized MAS precursor.

temperature, the characteristic vibration of cubic $\mathrm{MgO}$ increases. It can be seen that the intense characteristic vibration of cubic $\mathrm{MgO}$ exists in the band ranging from $500-1000 \mathrm{~cm}^{-1}$ with the absorption peak at $860 \mathrm{~cm}^{-1}$ indicating the complete formation of cubic $\mathrm{MgO}$. For the samples of the MAS spinel precursor calcined at $800{ }^{\circ} \mathrm{C}$ and $1200{ }^{\circ} \mathrm{C}$ (Figure $4 \mathrm{~d}$ and e), significant spectroscopic bands at $512,547,703$ and $799 \mathrm{~cm}^{-1}$ appear which are identified to be the characteristic absorption bands of MAS structure. With the increase of the calcination temperature, the absorption peaks are intensified exhibiting the totally formation of MAS phase.

The thermal decomposition of the citrate precursors and the phase transition of $\mathrm{MgO}$ and MAS spinel have been analyzed. The TG-DSC curves of the Mg precursor and MAS precursor are shown in Figure 5 and 6, respectively. For the thermal decomposition of the $\mathrm{Mg}$ precursor shown in Figure 5 , in the range of RT-250 ${ }^{\circ} \mathrm{C}$, an endothermic peak at about $230{ }^{\circ} \mathrm{C}$ with a mass loss of about $8 \%$ appears which may be associated to the vaporization of physically bound absorbed water. In the temperature region $250-700{ }^{\circ} \mathrm{C}$, a broadened and maximum exothermic peak at about $310{ }^{\circ} \mathrm{C}$ is relatively sharp and intense, accompanied by a drastic mass loss. It indicates the dehydration reaction of the citrate precursor and the decomposition of the precursor from $\mathrm{Mg}$ precursor to $\mathrm{MgO}$. The mass loss associated with this sharp exothermal reaction is about $70 \%$. The relatively broad endothermic peak at about $800{ }^{\circ} \mathrm{C}$ corresponds to the crystal growth of cubic $\mathrm{MgO}$. So the transformation of the cubic $\mathrm{MgO}$ occurs directly in amorphous $\mathrm{MgO}$ when calcined at a proper temperature. Therefore, the proper calcination temperature for the $\mathrm{Mg}$ precursor is determined to be $800{ }^{\circ} \mathrm{C}$ for the formation of high crystallized cubic $\mathrm{MgO}$. The TG-DSC curve of the as-synthesized MAS precursor is similar to that of the $\mathrm{Mg}$ precursor. However, in the RT-300 ${ }^{\circ} \mathrm{C}$, an endothermic peak at about $250{ }^{\circ} \mathrm{C}$ with a mass loss of about $4 \%$ appears which is associated to the vaporization of physically bound absorbed water. The maximum mass loss of the MAS precursor is obviously far less than that of the $\mathrm{Mg}$ precursor with the value of about $38 \%$. A relatively sharp endothermic peak at about $800{ }^{\circ} \mathrm{C}$ occurs which may be associated to the nucleation process of the MAS. The relatively broad endothermal bands with the peak at about $1130{ }^{\circ} \mathrm{C}$ in the temperature range of $1000-1200{ }^{\circ} \mathrm{C}$ may contribute to the crystal growth of the MAS structure.

\section{Conclusions}

In summary, fine $\mathrm{MgO}$ and MAS powders were synthesized using citrate precursors derived from magnesium chloride, aluminium nitrate and citrate. At about $400{ }^{\circ} \mathrm{C}$ citrate precursors decompose and $\mathrm{MgO}, \mathrm{MAS}$ are initially formed. The pure cubic $\mathrm{MgO}$ and MAS phases form at the heat treatment of $\mathrm{Mg}$ precursor and MAS precursor at 800 and $1200{ }^{\circ} \mathrm{C}$, respectively with the particle size in the range of nanometer and micrometer size. Further experimental results show that ball milling treatment can eliminate the conglomeration and size of the powders. From a practical point of view, the synthesis of fine $\mathrm{MgO}$ and MAS powders from less expensive precursors inorganic salts instead of alkoxide precursors following this reported could be of great interest.

\section{Acknowledgments}

This work was supported by the National Basic Research Program of China (863 Program, 2009AA03Z529) and the National Key Construction New Technique of China (2009-161).

\section{References}

1. Yuan YS, Wong MS and Wang SS. Solid-state processing and phase development of bulk $(\mathrm{MgO})_{w} / \mathrm{BPSCCO}$ high-temperature superconducting composite. Journal of Materials Research. 1996; 11:8-17.

2. Bhargava A, Alarco JA, Mackirmon IDR, Page D and IIyushechkin A. Synthesis and characterization of nanoscale magnesium oxide powders and their application in thick films of $\mathrm{Bi}_{2} \mathrm{Sr}_{2} \mathrm{CaCu}_{2} \mathrm{O}_{8}$. Materials Letters. 1998; 34:133-142.

3. Chhor K, Bocquet JF and Pommier C. Syntheses of submicron magnesium oxide powders. Materials Chemistry and Physics. 1995; 40:63-68.

4. Znaidi L, Chhor K and Pommier C. Batch and semi-continuous synthesis of magnesium oxide powders from hydrolysis and supercritical treatment of $\mathrm{Mg}\left(\mathrm{OCH}_{3} \mathrm{O}\right)_{2}$. Materials Research Bulletin. 1996; 31:1527-1535.

5. Alvarado E, Torres-Martinez LM, Fuentes AF and Quintana P. Preparation and characterization of $\mathrm{MgO}$ powders obtained from different magnesium salts and the mineral dolomite. Polyhedron. 2000; 19:2345-2351.

6. Ding Y, Zhang GT, Wu H, Hai B, Wang LB and Qian YT. Nanoscale magnesium hydroxide and magnesium oxide powders: control over size, shape, and structure via hydrothermal synthesis. Chemistry of Materials. 2001; 13:435-440.

7. Koper OB, Lagadic I, Volodin A and Klabunde KJ. Alkaline-earth oxide nanoparticles obtained by aerogel methods. Characterization and rational for unexpectedly high surface chemical reactivities. Chemistry of Materials. 1997; 9:2468-2480. 
8. Ganesh I, Bhattacharjee S, Saha BP, Johnson R, Rajeshwari K, Sengupta R et al. An efficient $\mathrm{MgAl}_{2} \mathrm{O}_{4}$ spinel additive for improved slag erosion and penetration resistance of high- $\mathrm{Al}_{2} \mathrm{O}_{3}$ and $\mathrm{MgO}-\mathrm{C}$ refractories. Ceramics International. 2002; 28:245-253.

9. Ganesh I, Johnson R, Rao GVN, Mahajan YR, Madavendra SS and Reddy BM. Microwave-assisted combustion synthesis of nanocrystalline $\mathrm{MgAl}_{2} \mathrm{O}_{4}$ spinel powder. Ceramics International. 2005; 31:67-74.
10. Pati RK and Pramanik P. Low-temperature chemical synthesis of nanocrystalline $\mathrm{MgAl}_{2} \mathrm{O}_{4}$ spinel powder. Journal of American Ceramics Society. 2000; 83:1822-1824.

11. Li J, Pan YB, Xiang CS, Ge QM and Guo JK. Low temperature synthesis of ultrafine $\alpha-\mathrm{Al}_{2} \mathrm{O}_{3}$ powder by a simple aqueous sol-gel process. Ceramics International. 2006; 32:587-591. 
